\title{
Upgrading of Phosphate Ore Wastes of El-Nasr Mining Company, Egypt
}

\author{
Mohamed Abuel Kasem Mohamed ${ }^{1}$, Galal Abd El Azim Ibrahim ${ }^{1}$, \\ Ahmed Mohamed Ebrahim Rizk ${ }^{1}$, Mahmoud Mohamed Ahmed ${ }^{1}$, Ahmed Mohamed El Nozahi ${ }^{2}$, \\ Nagui Aly Abdel-khalek ${ }^{3}$, Hasan Bakheat ${ }^{4}$ \\ ${ }^{1}$ Department of Mining and Metallurgical Engineering, Faculty of Engineering, Assiut University, Assiut, Egypt \\ ${ }^{2}$ Council of Research for Industrial Technologies in the Egyptian Academy of Scientific Research and Technology, Cairo, Egypt \\ ${ }^{3}$ Central Metallurgical Research and Development Institute (CMRDI), Cairo, Egypt \\ ${ }^{4}$ Exploration and Evaluation of Mineral Deposit, Egyptian Mineral Resources Authority, Cairo, Egypt
}

Email address:

mohamabu2001@gmail.com (M. A. K. Mohamed)

\section{To cite this article:}

Mohamed Abuel Kasem Mohamed, Galal Abd El Azim Ibrahim, Ahmed Mohamed Ebrahim Rizk, Mahmoud Mohamed Ahmed, Ahmed Mohamed El Nozahi, Nagui Aly Abdel-khalek, Hasan Bakheat. Upgrading of Phosphate Ore Wastes of El-Nasr Mining Company, Egypt. International Journal of Mineral Processing and Extractive Metallurgy. Vol. 3, No. 2, 2018, pp. 37-46. doi: 10.11648/j.ijmpem.20180302.14

Received: July 25, 2018; Accepted: August 14, 2018; Published: October 8, 2018

\begin{abstract}
Phosphates are vital nonrenewable resources. The treatment of phosphate ore wastes of El-Nasr Mining Company, Sepaeya, Egypt aims to upgrade $\mathrm{P}_{2} \mathrm{O}_{5}$ percent, adds a new economic value, development of the Egyptian national income, and aids to clean the mine district. The main aim of this paper is to compare different processing alternatives methods to concentrate and upgrade of phosphate ore tailings assayed 18.37\% of El-Nasr Mining Company, Sepaeya, Egypt. The concentration of wastes not only add an economic value but also safe the human, animals, and plants. Two options of sizes obtained from grinding and sieving were separated to obtain the highest grade of $\mathrm{P}_{2} \mathrm{O}_{5}$ with the greatest recovery. The first option (i.e. sizes below $100 \mu \mathrm{m}$ ) gave $\mathrm{P}_{2} \mathrm{O}_{5}$ percent of $23.88 \%, \mathrm{P}_{2} \mathrm{O}_{5}$ recovery of $42.37 \%$, and weight recovery equals to $33.68 \%$. The second option (i.e. sizes below $160 \mu \mathrm{m}$ ) gave $\mathrm{P}_{2} \mathrm{O}_{5}$ percent of $22.52 \%, \mathrm{P}_{2} \mathrm{O}_{5}$ recovery of $53.25 \%$, and weight recovery equals to $44.88 \%$. The calcination process raised $\mathrm{P}_{2} \mathrm{O}_{5}$ to 22.4 with weight recovery $83.75 \%$, and $\mathrm{P}_{2} \mathrm{O}_{5}$ recovery of 99.10\%. Leaching process using acetic acid gave the best results at the following conditions: a)solid to liquid ratio $15 \%$ where the percent of $\mathrm{P}_{2} \mathrm{O}_{5}$ raised from $18 \%$ to $22.23 \%$ with weight recovery about $86 \%$, b) Agitation time 15 minutes where the percent of $\mathrm{P}_{2} \mathrm{O}_{5}$ raised from $18 \%$ to $22.35 \%$ with weight recovery about $86 \%$, c) Agitation speed $1200 \mathrm{rpm}$ where the percent of $\mathrm{P}_{2} \mathrm{O}_{5}$ increased from $18 \%$ to $22.23 \%$ with weight recovery about $86 \%$, d) Acid to ore ratio $16.7 \%$ where the percent of $\mathrm{P}_{2} \mathrm{O}_{5}$ increased from $18 \%$ to $21.44 \%$ with weight recovery about $88.7 \%$. The leaching process on size $-100 \mu \mathrm{m}$ raised $\mathrm{P}_{2} \mathrm{O}_{5} \%$ from $23.88 \%$ to $28.44 \%$ with weight recovery $84 \%$. The weight recovery and $\mathrm{P}_{2} \mathrm{O}_{5}$ recovery with respect to the original feed were $28.29 \%$ and $42.39 \%$, respectively.
\end{abstract}

Keywords: Phosphate, Wastes, Crushing, Grinding, Sieving, Calcination, Leaching

\section{Introduction}

The annual consumption of phosphates approached 150 million tons. Phosphates are vital nonrenewable resources [1]. They are essential components in agricultural fertilizers and phosphorous-based chemicals [2]. They are also very important constituents in animal feed stocks. About $95 \%$ of the phosphate produced around the world is consumed in the fertilizer industry [3-4].
Phosphate ores in terms of quality and $\mathrm{P}_{2} \mathrm{O}_{5}$ grade can be divided into three groups: low grade ores $\left(12-16 \% \mathrm{P}_{2} \mathrm{O}_{5}\right)$, intermediate-grade ores $\left(17-25 \% \mathrm{P}_{2} \mathrm{O}_{5}\right)$, and high-grade ores $\left(26-35 \% \mathrm{P}_{2} \mathrm{O}_{5}\right)$ [5].

Physical as well as thermal treatment techniques are used for concentrating the run-of-mine phosphates. The processing techniques of phosphate ores depend mostly on the type of 
associated gangue minerals present in the mined rock [6]. The most common gangue minerals in phosphate ores are quartz, chert, clay, feldspar, mica, calcite, and dolomite [7].

In some cases, simple, inexpensive techniques are enough to produce the required grade. For example, crushing and screening is used to get rid of the coarse hard siliceous material, and attrition scrubbing and desliming is used to remove the clayey fine fraction.

If silica is the main gangue material, single-stage or double-stage flotation is the conventional mineral processing technique used in this case. The calcareous types of phosphate ores are extremely difficult to concentrate via flotation due to the similar physicochemical surfaces characteristics of the main constituents, carbonates and phosphates [6, 8-9].

In Egypt phosphate reserves are present in three localities namely; the eastern desert, Nile valley, and the new valley in western desert. Currently, phosphate ores are being mined from Nile valley areas. The mining companies export the fractions of high grade (over $30 \% \mathrm{P}_{2} \mathrm{O}_{5}$ ) while the fractions of low grade is being rejected. This is because such fractions contain different gangue minerals such as calcite and silica.

This paper aimed to compare different processing alternatives methods to concentrate and upgrade of phosphate ore tailings assayed $18.37 \%$ of El-Nasr Mining Company, Sepaeya, Egypt. The concentration of wastes not only add an economic value but also safe the human, animals, and plants.

\section{Petrographical and Mineralogical Study of the Samples}

Thin and polished sections of phosphate ore wastes of Sepaeya mines were prepared for petrographical and mineralogical investigation. The study revealed that these wastes are presented by phosphatic rock (phosphorite).

Microscopically, the phosphate ore wastes of Sepaeya mines are moderately hard, compact and of creamy color with pale yellow and brown spots.

Microscopically, in thin section, it is shown that the rock is fine to coarse grained and composed mainly of cellophane \& carbonate minerals as essential constituents associated with minor amounts of iron oxides and quartz. Cellophane (represent about $40 \%$ of total minerals constituents) occurs as fine to coarse-grained in the form of rounded to sub-rounded brownish pellets, fish teeth, scales, bones, fossil shells and fragments. Cellophane embedded in very fine-grained matrix of carbonate minerals and sometimes stained and surrounded by iron oxides. The matrix of the sample is composed of very fine-grained calcite (micrite) and/or dolomite and sometimes stained by traces of iron oxides in some parts. Some fossil shells and fragments are present in the sample as elongated and curved filaments scattered in the carbonate matrix. Quartz presents as a very fine to fine-grained, surrounded to sub-angular in shape and scattered in the very fine- grained matrix of carbonates. Iron oxides are present in minor amounts in the rock.

The mineralogical study of the polished section revealed that the opaque minerals are represented by minor amounts of hematite and goethite. Hematite is essential opaque mineral occurs as very fine to fine grained aggregates, anhedral to subhedral in form. It also presents as irregular patches, thin films lining the essential minerals and also as a staining mineral over some grains cellophane and carbonates. Hematite sometimes replaces the internal structure of the biogenic material. But goethite presents as very fine to fine grained anhedral crystals in rare amounts; it is formed as alteration product after hematite where relics of hematite are still preserved in goethite.

\section{Experimental}

\subsection{Sample Preparation}

i- The head sample was mixed thoroughly and divided into 8 similar parts; each part represents about $5 \mathrm{~kg}$.

ii- The first part which having $\mathrm{P}_{2} \mathrm{O}_{5}$ percent about $18.37 \%$ was sieved onscreen of5 $\mathrm{mm}$ size. The oversize and undersize were chemically analyzed for $\mathrm{P}_{2} \mathrm{O}_{5}$ percent. The results are shown in Table 1and Figure 1. From these results it can be seen that the percent of $\mathrm{P}_{2} \mathrm{O}_{5}$ in oversize was about $18.34 \%$, while in undersize was $21.76 \%$.

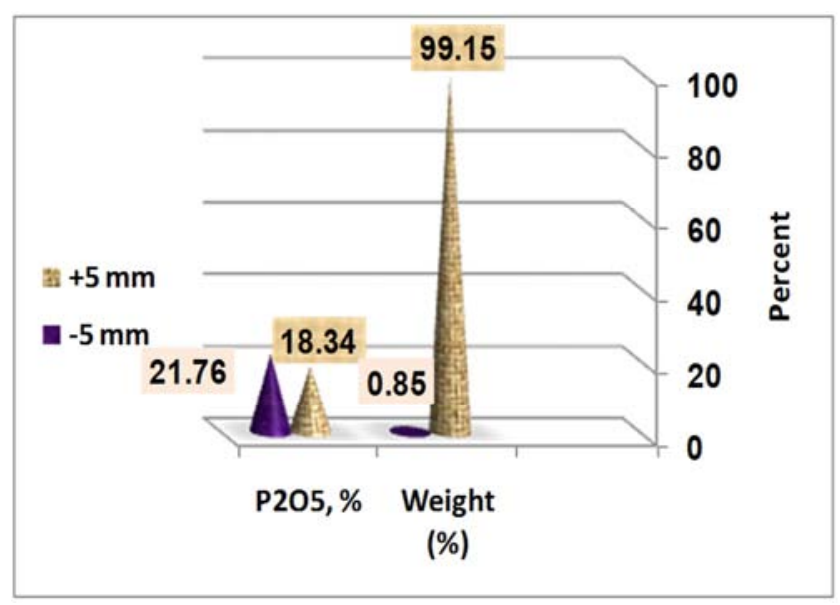

Figure 1. Results of sieving original sample on screen of size $5 \mathrm{~mm}$.

Table 1. Results of sieving the original sample on screen of size $5 \mathrm{~mm}$.

\begin{tabular}{llll}
\hline Screen size, $\mathbf{m m}$ & Weight, $\mathbf{g}$ & Weight, $\%$ & $\mathbf{P}_{2} \mathbf{O}_{5}, \mathbf{\%}$ \\
\hline+5 & 5007 & 99.15 & 18.34 \\
-5 & 43 & 0.85 & 21.76 \\
Head Sample & & & 18.37 \\
\hline
\end{tabular}




\subsection{Procedure}

In this paper, different alternative processes were carried out to concentrate and upgrade of phosphate ore tailings as follows:

i. The oversize resulted from sieving the original sample was comminuted according to the flowsheet shown in Figure 2. Two representative samples of undersize $-5 \mathrm{~mm}$ were subjected to sieving and each size fraction was chemically analyzed. Results are shown in Table 2.

ii. A representative sample of crushed ore $-5 \mathrm{~mm}$ was ground using hammer crusher in closed circuit with screen 1 $\mathrm{mm}$. The ground sample $(-1 \mathrm{~mm})$ was sieve analyzed and each size fraction was chemically analyzed.

iii. The ground sample $(-1 \mathrm{~mm})$ was subjected to calcination at $740^{\circ} \mathrm{C}$ for one hour. The sample obtained from calcination was quenched with water in conditioning tank and agitated for $15 \mathrm{~min}$. after which it was filtrated and dried at $105^{\circ} \mathrm{C}$ for 24 hours and then chemically analyzed for $\mathrm{P}_{2} \mathrm{O}_{5}$.

iv. A representative sample of crushed ore $-5 \mathrm{~mm}$ was ground using hammer crusher in closed circuit with screen 1 $\mathrm{mm}$. The ground sample $(-1 \mathrm{~mm})$ was ground again in disc mill until $-200 \mu \mathrm{m}$. The product was de-slimed with screen 38 $\mu \mathrm{m}$. The leaching experiments were carried out on fraction ($250+38) \mu \mathrm{m}$ which having $\mathrm{P}_{2} \mathrm{O}_{5}$ percent of $18 \%$. The tests were executed at different variables, i.e. solid to liquid ratio, leaching time, agitation speed, and acid to ore ratio.

$\mathrm{v}$. Different sizes resulted from grinding process $(-250 \mu \mathrm{m}$ and $-100 \mu \mathrm{m})$ were leached at acid to ore ratio $10 \%$, leaching time 15 minutes, agitation speed $1200 \mathrm{rpm}$, and solid to liquid ratio of $15 \%$

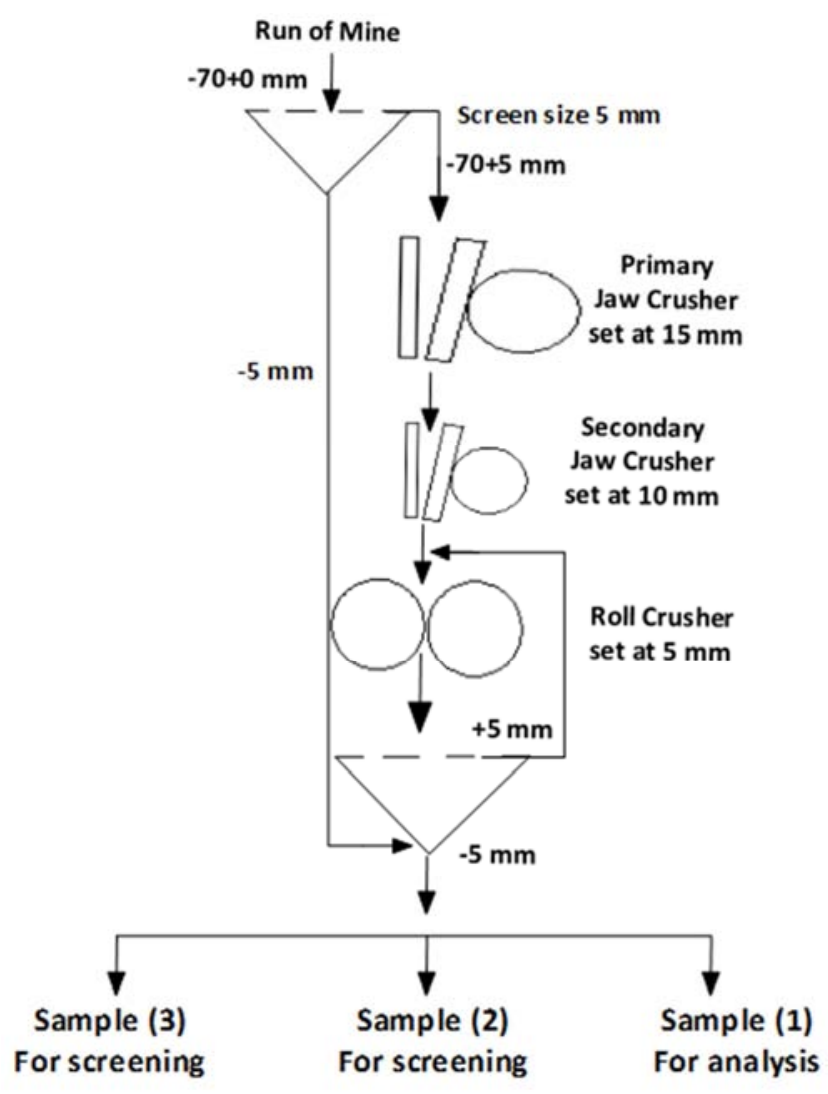

Figure 2. Flowsheet of crushing original sample.

Table 2. Sieve and chemical analysis of samples resulted from crushing process.

\begin{tabular}{lllllll}
\hline \multirow{2}{*}{ Analysis No. } & \multirow{2}{*}{ Size, $\mathbf{m m}$} & $\begin{array}{l}\text { Sample (2) } \\
\text { weight, } \mathbf{g}\end{array}$ & $\begin{array}{l}\text { Sample (3) } \\
\text { weight, } \mathbf{g}\end{array}$ & & Collected sample & \\
\cline { 5 - 7 } & & 53.37 & 38.09 & 91.46 & 28.42 & \\
\hline 1 & $(-5+3.15)$ & 54.71 & 48.17 & 102.88 & 31.97 & 18.74 \\
2 & $(-3.15+2)$ & 13.31 & 16.32 & 29.63 & 9.21 & 18.69 \\
3 & $(-2+1.25)$ & 16.57 & 24.14 & 40.71 & 12.65 & 17.97 \\
4 & $(-1.25+0.63)$ & 8.29 & 13.13 & 4.08 & 18.09 \\
5 & $(-0.63+0.4)$ & 4.84 & 6.75 & 10.42 & 3.24 & 19.25 \\
6 & $(-0.4+0.25)$ & 3.67 & 7.97 & 11.66 & 3.62 & 21.08 \\
7 & $(-0.25+0.16)$ & 3.69 & 4.72 & 6.95 & 2.16 & 20.64 \\
8 & $(-0.16+0.1)$ & 2.23 & 10.00 & 15.00 & 4.66 & 21.71 \\
9 & $(-0.1)$ & 5.00 & 164.45 & 321.84 & 100.00 & 21.38 \\
Sum & & 157.39 & &
\end{tabular}

\section{Results and Discussion}

\subsection{Crushing and Sieving of the Head Sample}

This technique utilizes the differences in differential friability between phosphate minerals and associated gangue and cementing matrix (carbonates, silica, and silicates). In most cases, phosphate minerals are friable while gangue minerals are hard. By crushing and screening, the fine fraction will be rich in phosphates, but high percentage of $\mathrm{P}_{2} \mathrm{O}_{5}$ may be lost in the coarse fraction [10].

Cumulative weight $\%$ passed, cumulative $\mathrm{P}_{2} \mathrm{O}_{5} \%$ passed, and cumulative $\%$ of $\mathrm{P}_{2} \mathrm{O}_{5}$ recovery of samples in Table 2 were calculated and tabulated in Table 3 and shown in Figure 3.

Table 3. Cumulative weight \% passed, cumulative $P_{2} \mathrm{O}_{5} \%$ passed, and cumulative $\%$ of $\mathrm{P}_{2} \mathrm{O}_{5}$ recovery of samples resulted from crushing process.

\begin{tabular}{llllll}
\hline Analysis No. & Size, $\mathbf{~ m m}$ & Wt.\% & Cum. wt.\% passed & Cum. $\mathbf{P}_{\mathbf{2}} \mathbf{O}_{\mathbf{5}} \mathbf{\%}$ passed & Cum.\% of $\mathbf{P}_{\mathbf{2}} \mathbf{O}_{\mathbf{5}}$ recovery \\
\hline 1 & -5 & 28.42 & 100.00 & 18.93 & 100.00 \\
2 & -3.15 & 31.97 & 71.58 & 19.00 & 71.86 \\
3 & -2 & 9.21 & 39.62 & 19.24 & 40.29 \\
\hline
\end{tabular}




\begin{tabular}{llllll}
\hline Analysis No. & Size, $\mathbf{m m}$ & Wt.\% & Cum. wt.\% passed & Cum. $\mathbf{P}_{\mathbf{2}} \mathbf{O}_{\mathbf{5}} \%$ passed & Cum.\% of $\mathbf{P}_{\mathbf{2}} \mathbf{O}_{\mathbf{5}}$ recovery \\
\hline 4 & -1.25 & 12.65 & 30.41 & 19.63 & 31.54 \\
5 & -0.63 & 4.08 & 17.76 & 20.73 & 19.45 \\
6 & -0.4 & 3.24 & 13.68 & 21.17 & 15.30 \\
7 & -0.25 & 3.62 & 10.44 & 21.19 & 11.69 \\
8 & -0.16 & 2.16 & 6.82 & 21.48 & 7.74 \\
9 & -0.1 & 4.66 & 4.66 & 21.38 & 5.26 \\
\hline
\end{tabular}
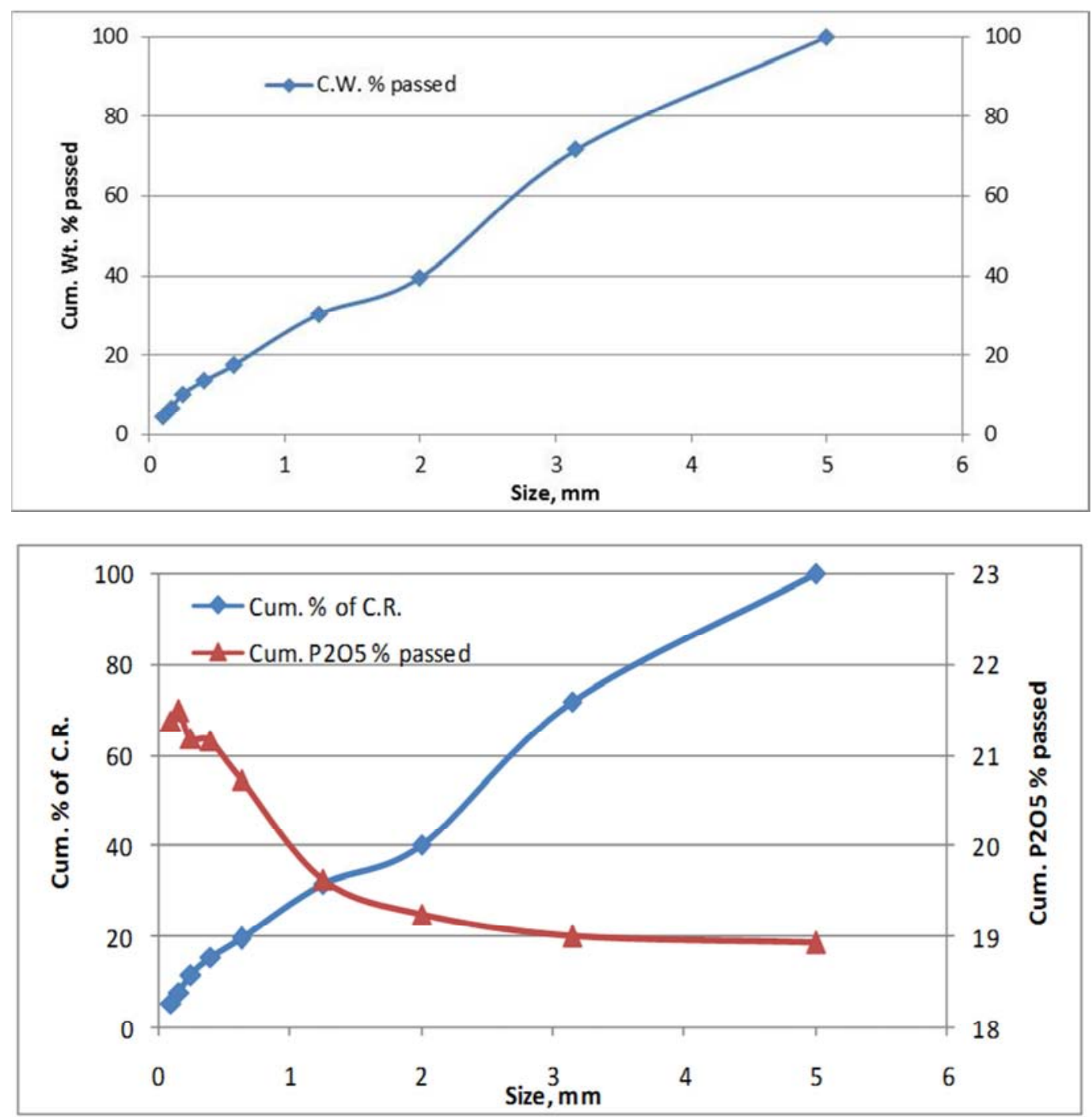

Figure 3. Cumulative weight \% passed, cumulative $\mathrm{P}_{2} \mathrm{O}_{5} \%$ passed, and cumulative $\%$ of $\mathrm{P}_{2} \mathrm{O}_{5}$ recovery of samples resulted from crushing process.

Three alternatives of samples obtained from crushing and sieving were compared to obtain the highest grade of $\mathrm{P}_{2} \mathrm{O}_{5}$ with the greatest recovery. The results are shown in Figure 4 and tabulated in Table 4. From the results of different options, it was revealed that the second option (i.e. collection of sizes below $0.400 \mathrm{~mm}$ ) was the best one where the percent of $\mathrm{P}_{2} \mathrm{O}_{5}$ is $21.17 \%$, recovery of $\mathrm{P}_{2} \mathrm{O}_{5}$ is $15.30 \%$, and weight recovery equals to $13.68 \%$. These results assured that the crushing process did not succeed to produce a suitable grade and recovery.

Table 4. Different alternatives of samples obtained from crushing and sieving.

\begin{tabular}{lllll}
\hline Option No. & Particle size, $\mathbf{~ m m}$ & Wt. rec.\% & $\mathbf{P}_{\mathbf{2}} \mathbf{O}_{\mathbf{5}} \mathbf{\%}$ & Recovery of $\mathbf{P}_{\mathbf{2}} \mathbf{O}_{\mathbf{5}} \mathbf{\%}$ \\
\hline O1 & $(-0.630+0)$ & 17.76 & 20.73 & 19.45 \\
O2 & $(-0.400+0)$ & 13.68 & 21.17 & 15.3 \\
O3 & $(-0.250+0)$ & 10.44 & 21.19 & 11.69 \\
\hline
\end{tabular}




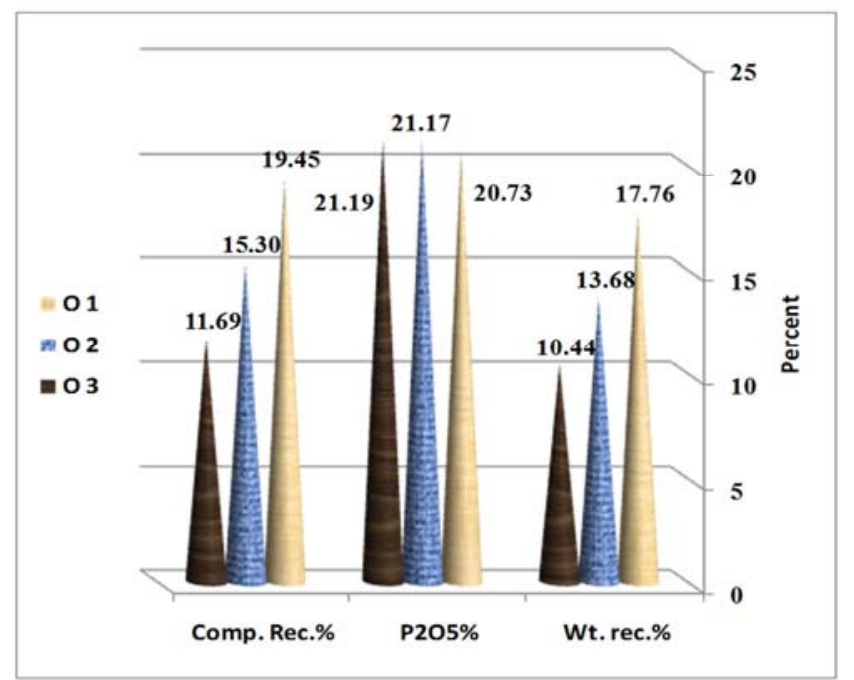

\subsection{Calcination of Original Sample}

Calcination is the process of heating the ore to a high temperature ranging from $800^{\circ}$ to $1000^{\circ} \mathrm{C}$ to decompose the $\mathrm{CaCO}_{3}$ and $\mathrm{MgCO}_{3}$ to $\mathrm{CaO}, \mathrm{MgO}$ and gaseous $\mathrm{CO}_{2}$. The $\mathrm{CaO}$ and $\mathrm{MgO}$ formed are then removed as hydroxides by quenching the calcined product in water and washing. The most common chemical reagent used to enhance the removal of calcium and magnesium hydroxides is the ammonium chloride, $\mathrm{NH} 4 \mathrm{Cl}$ [11].

The results of calcination process are tabulated in Table 5 and Figure 5. From these results; it can be seen that the calcination process raised the $\mathrm{P}_{2} \mathrm{O}_{5}$ from $18.93 \%$ to $22.4 \%$, with weight recovery $83.75 \%$, and $\mathrm{P}_{2} \mathrm{O}_{5}$ recovery $99.10 \%$, due to the decomposition of calcium and magnesium carbonates.

Figure 4. Different alternatives of samples obtained from crushing and sieving.

Table 5. Results of calcination process.

\begin{tabular}{llllll}
\hline Test No. & Sample & Weight, $\mathbf{g}$ & Weight, $\%$ & $\mathbf{P}_{\mathbf{2}} \mathbf{O}_{\mathbf{5}} \mathbf{\%}$ & Recovery of $\mathbf{P}_{\mathbf{2}} \mathbf{O}_{\mathbf{5}}, \mathbf{\%}$ \\
\hline 1 & Original sample before calcination & 103.6 & 100 & 18.93 & 100 \\
2 & Original sample after calcination & 86.77 & 83.75 & 22.40 & 99.10 \\
\hline
\end{tabular}

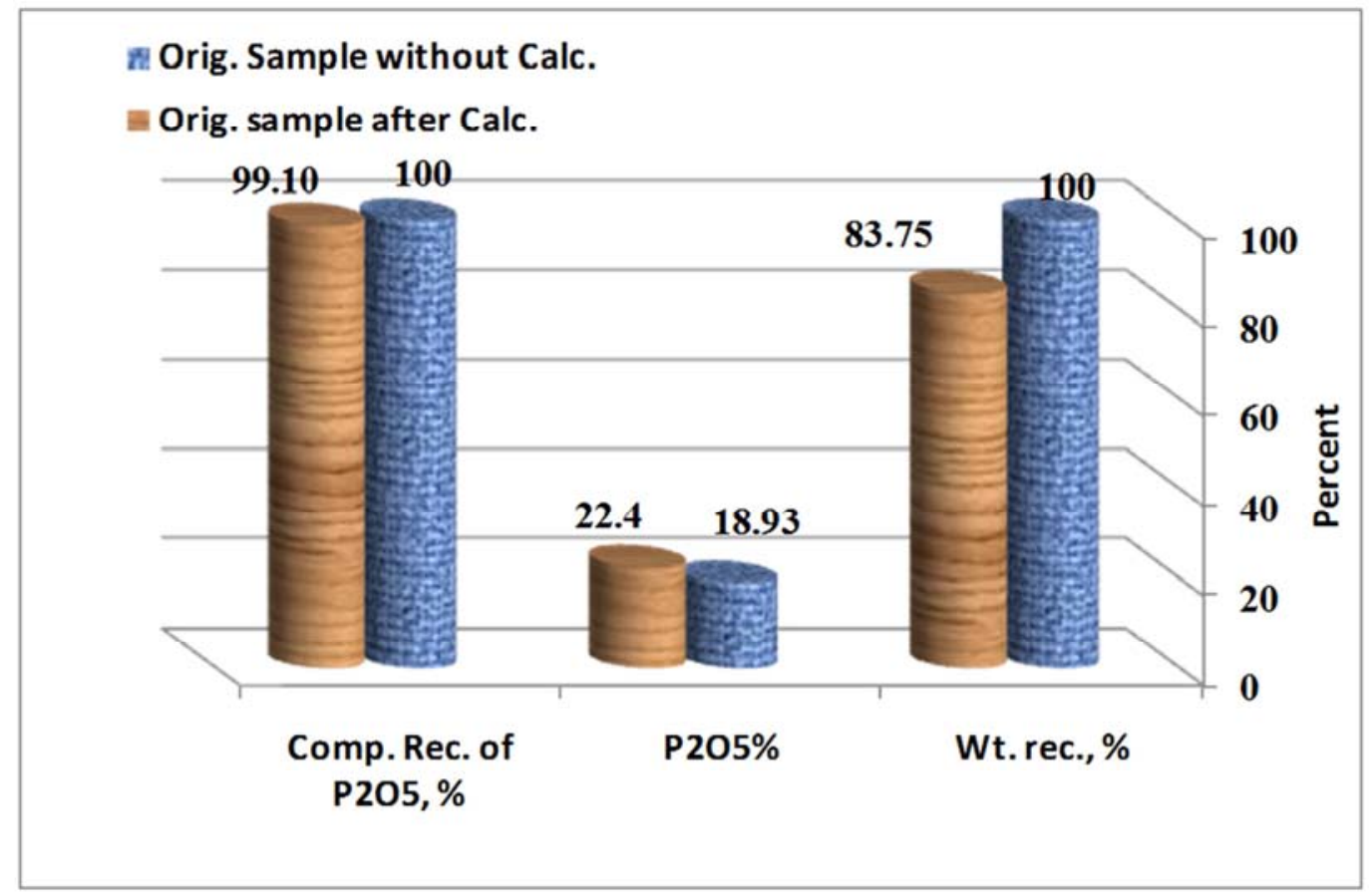

Figure 5. Results of calcination process.

\subsection{Effect of Grinding Process}

The obtained results were illustrated in Table 6 and Figure 6. Two options of sizes obtained from grinding and sieving were proposed to obtain the highest grade of $\mathrm{P}_{2} \mathrm{O}_{5}$ with the greatest recovery. The results are shown in Table 7 and Figure 7. From studying the different options, it was cleared that the first option (i.e. sizes below $100 \mu \mathrm{m}$ ) gave a percent of $\mathrm{P}_{2} \mathrm{O}_{5} 23.88 \%, \mathrm{P}_{2} \mathrm{O}_{5}$ recovery $42.37 \%$, and weight recovery equals to $33.68 \%$. The second option (i.e. sizes below 160 $\mu \mathrm{m})$ gave $\mathrm{P}_{2} \mathrm{O}_{5}$ percent of $22.52 \%, \mathrm{P}_{2} \mathrm{O}_{5}$ recovery of $53.25 \%$, and weight recovery equals to $44.88 \%$. These results revealed that the grinding and sieving processes succeeded to produce a suitable grade and recovery. 
Table 6. Cumulative weight\% passed, cumulative $\mathrm{P}_{2} \mathrm{O}_{5} \%$ passed, and cumulative\% of $\mathrm{P}_{2} \mathrm{O}_{5}$ recovery of grinding samples.

\begin{tabular}{llllllll}
\hline Test No. & Size, $\mathbf{m m}$ & Weight, $\%$ & $\mathbf{P}_{\mathbf{2}} \mathbf{O}_{\mathbf{5}} \%$ & Size, $\mathbf{m m}$ & Cum. wt.\% Passed & Cum. $\mathbf{P}_{\mathbf{2}} \mathbf{O}_{\mathbf{5}} \mathbf{\%}$ Passed & Cum. rec. of $\mathbf{P}_{\mathbf{2}} \mathbf{O}_{\mathbf{5}}$ \% \\
\hline 1 & $(-1+0.63)$ & 9.09 & 12.93 & -1.00 & 100 & 18.98 & 100.00 \\
2 & $(-0.63+0.40)$ & 14.29 & 16.03 & -0.63 & 90.91 & 20.25 & 93.81 \\
3 & $(-0.40+0.25)$ & 16.75 & 16.08 & -0.40 & 76.62 & 21.42 & 81.74 \\
4 & $(-0.25+0.16)$ & 14.99 & 18.11 & -0.25 & 59.87 & 22.52 & 53.55 \\
5 & $(-0.16+0.10)$ & 11.2 & 18.43 & -0.16 & 44.88 & 23.88 & 42.37 \\
6 & $(-0.10+0)$ & 33.68 & 23.88 & -0.10 & 33.68 & & \\
Sum & & 100.00 & 18.98 & & & & \\
\hline
\end{tabular}
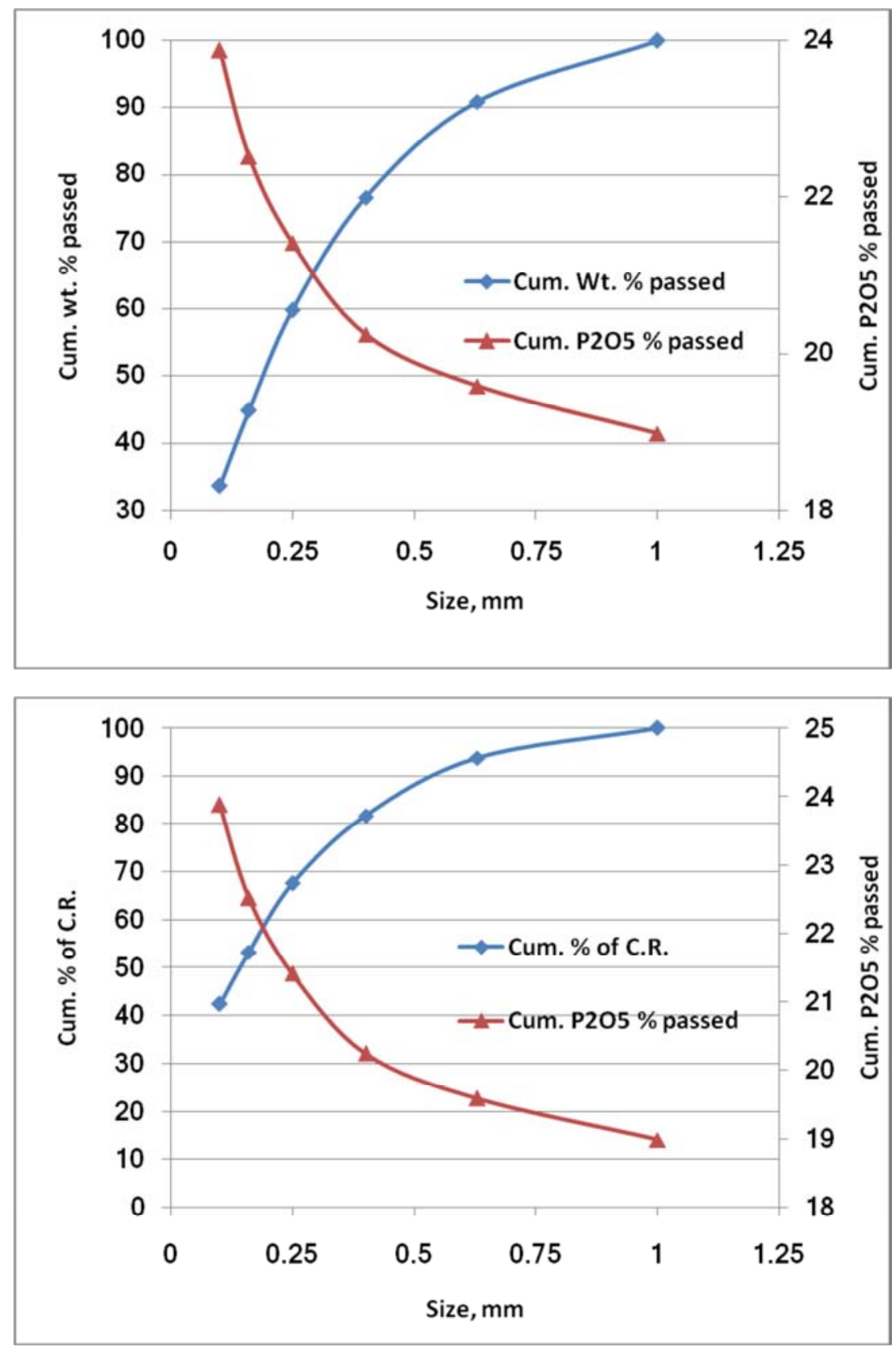

Figure 6. Cumulative weight\% passed, cumulative $\mathrm{P}_{2} \mathrm{O}_{5} \%$ passed, and cumulative\% of $\mathrm{P}_{2} \mathrm{O}_{5}$ recovery of samples resulted from grinding process.

Table 7. Different options of samples obtained from grinding and sieving processes.

\begin{tabular}{lllll}
\hline Option & Size, $\mathbf{m m}$ & Weight recovery, $\%$ & $\mathbf{P}_{\mathbf{2}} \mathbf{O}_{\mathbf{5}}, \mathbf{\%}$ & $\mathbf{P}_{\mathbf{2}} \mathbf{O}_{\mathbf{5}}$ rec., $\%$ \\
\hline O1 & $(-0.100+0)$ & 33.68 & 23.88 & 42.37 \\
O2 & $(-0.160+0)$ & 44.88 & 22.52 & 53.25 \\
\hline
\end{tabular}




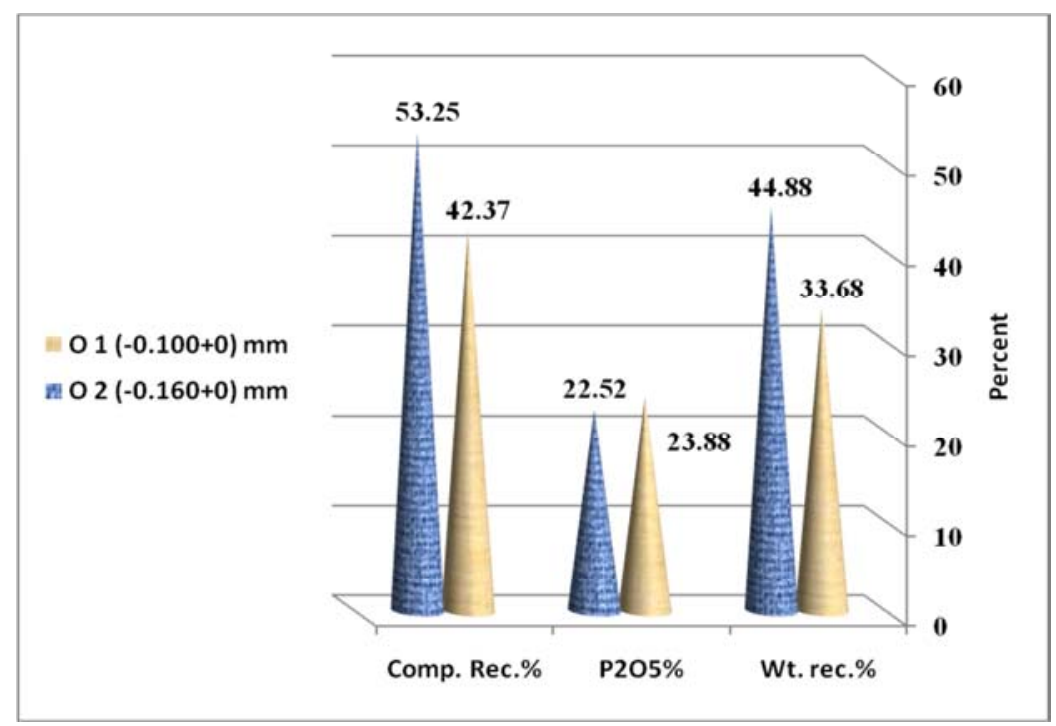

Figure 7. Different options of samples obtained from grinding and sieving processes.

Table 8 and Figure 8 illustrate the final results of grinding process. From these results it can be seen that the fraction ($1+0.630)$ should be sent to the waste dump because of the lower percent of $\mathrm{P}_{2} \mathrm{O}_{5}$. An attrition process may be carried out to the fraction $(-0.630+0.100)$.

Table 8. Final results of grinding and sieving processes.

\begin{tabular}{llll}
\hline Size, $\mathbf{~ m m}$ & Weight, $\%$ & $\mathbf{P}_{\mathbf{2}} \mathbf{O}_{\mathbf{5}}, \mathbf{\%}$ & Remarks \\
\hline$(-1+0.630)$ & 9.09 & 12.93 & To waste dump \\
$(-0.630+0.100)$ & 57.23 & 17.06 & To attrition process \\
$(-0.100)$ & 33.68 & 23.88 & Final product \\
\hline
\end{tabular}

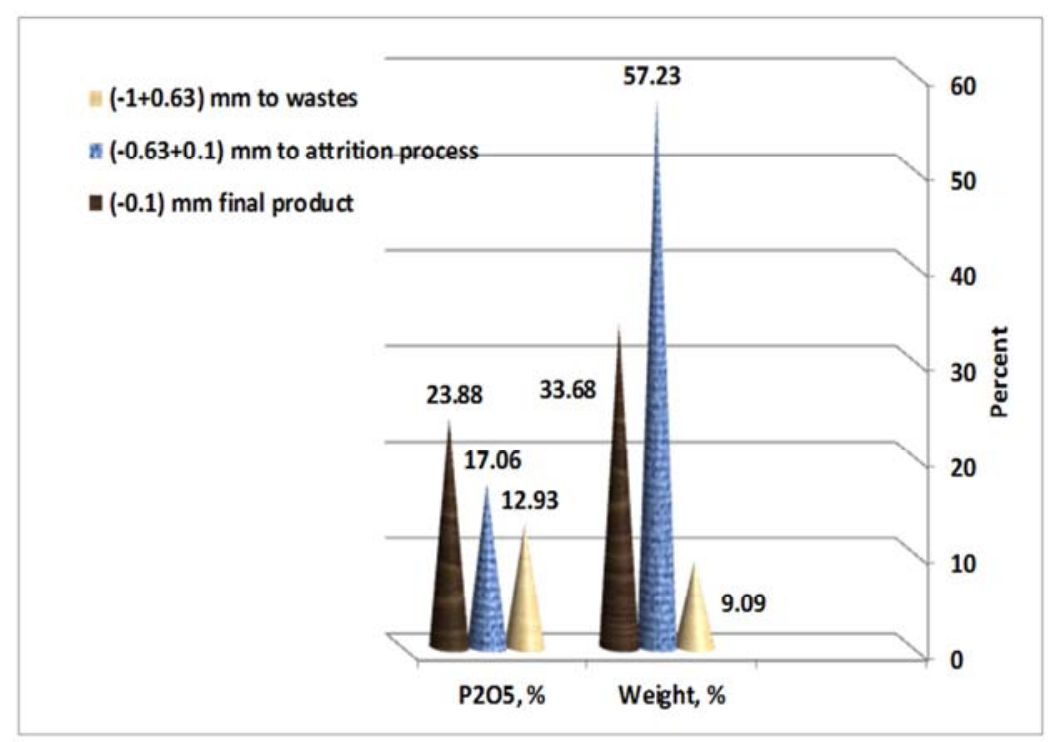

Figure 8. Final results of grinding processes.

\subsection{Leaching Process with Acetic Acid}

Calcium and magnesium carbonates are readily dissolvable in both mineral acids (strong acids) and organic acids (weak acids). In the case of calcareous phosphate ores, although mineral acids dissolve carbonates at high reaction rates, they also attack the phosphorus bearing minerals and cause losses in the $\mathrm{P}_{2} \mathrm{O}_{5}$ content of the ore if the intention is only to upgrade the ore not to dissolve the phosphates. To avoid this problem, organic acids have been studied as carbonate leaching agents although their reaction rates are slow [12-13].

These organic acids may be expensive and will certainly add to the production cost. On the other hand, they are selective to leaching carbonates, their capital cost is low, they do not cause environmental hazards, and they can be recycled [12-13]. The organic acids most commonly used in carbonate 
leaching are: acetic acid, citric acid, and formic acid.

The final results are shown in Table 9 and Figures 9 through 12 . The different parameters studied were as follows:

a. The solid to liquid ratio was changed from $10 \%$ to $30 \%$ at fixed agitation speed of $1200 \mathrm{rpm}$, constant leaching time, and acid to ore ratio $10 \%$ at 30 minutes. From these results, it can be seen that the best values were given at solid to liquid ratio $15 \%$ where the percent of $\mathrm{P}_{2} \mathrm{O}_{5}$ raised from $18 \%$ to $22.23 \%$ with weight recovery about $86 \%$.

b. The leaching time was changed with values 15,30 , and 45 minutes at fixed agitation speed of $1200 \mathrm{rpm}$, constant solid to liquid ratio of $15 \%$, and acid to ore ratio $10 \%$. From these results, it can be seen that the best values were obtained at 15 minutes where the percent of $\mathrm{P}_{2} \mathrm{O}_{5}$ raised from $18 \%$ to $22.35 \%$ with weight recovery about $86 \%$.

c. The leaching agitation speed was changed with values 800,1200 , and $1800 \mathrm{rpm}$ at fixed leaching time of 30 minutes, constant solid to liquid ratio of $15 \%$, and acid to ore ratio $10 \%$. From these results, it can be shown that the best values were obtained at $1200 \mathrm{rpm}$ where the percent of $\mathrm{P}_{2} \mathrm{O}_{5}$ increased from $18 \%$ to $22.23 \%$ with weight recovery about $86 \%$.

d. The values of acid to ore ratio were changed with values $10 \%, 16.7 \%$, and $167.7 \%$ at leaching time 30 minutes, agitation speed $1200 \mathrm{rpm}$, and constant solid to liquid ratio of $15 \%$. From these results, it can be revealed that the best values were obtained at acid to ore ratio $16.7 \%$ where the percent of $\mathrm{P}_{2} \mathrm{O}_{5}$ increased from $18 \%$ to $21.44 \%$ with weight recovery about $88.7 \%$.

Table 9. Final results of leaching process.

\begin{tabular}{|c|c|c|c|c|c|c|}
\hline Exp. No. & $\mathrm{S} / \mathrm{L}$ ratio, $\%$ & Leaching time, min. & Agitation speed, rpm & Acid/ore ratio, $\%$ & Weight recovery,\% & $\mathrm{P}_{2} \mathrm{O}_{5}, \%$ \\
\hline 1 & 10 & 30 & 1200 & 10 & 86 & 22.1 \\
\hline 2 & 15 & 30 & 1200 & 10 & 86 & 22.23 \\
\hline 3 & 30 & 30 & 1200 & 10 & 85.3 & 21.58 \\
\hline 4 & 15 & 15 & 1200 & 10 & 86 & 22.35 \\
\hline 5 & 15 & 30 & 1200 & 10 & 86 & 22.23 \\
\hline 6 & 15 & 45 & 1200 & 10 & 85.5 & 21.58 \\
\hline 7 & 15 & 30 & 800 & 10 & 85.3 & 21.9 \\
\hline 9 & 15 & 30 & 1800 & 10 & 85.7 & 21.77 \\
\hline 10 & 15 & 30 & 1200 & 10 & 93.3 & 20.27 \\
\hline 11 & 15 & 30 & 1200 & 16.7 & 88.7 & 21.44 \\
\hline 12 & 15 & 30 & 1200 & 167.7 & 85.3 & 20.92 \\
\hline
\end{tabular}

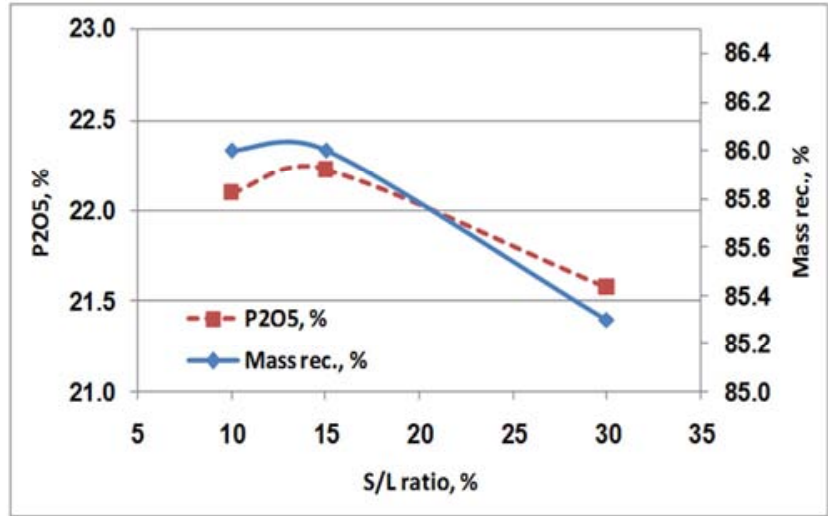

Figure 9. Effect of solid to liquid ratio on weight recovery and $\mathrm{P}_{2} \mathrm{O}_{5} \%$.

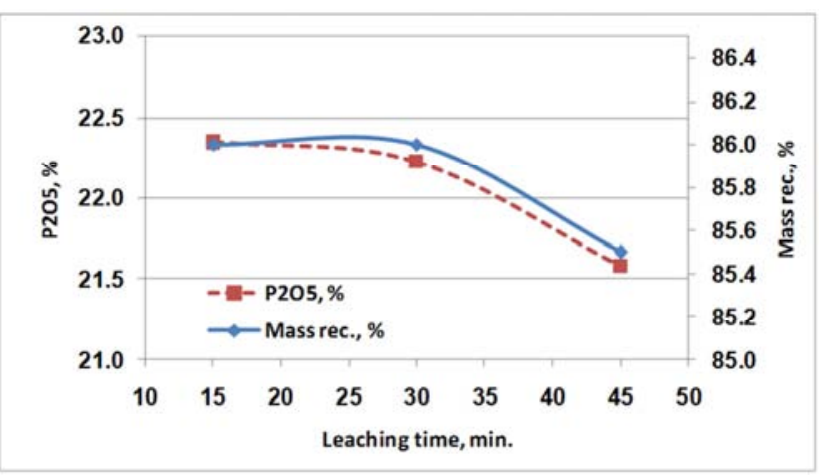

Figure 10. Effect of leaching time on weight recovery and $\mathrm{P}_{2} \mathrm{O}_{5} \%$.

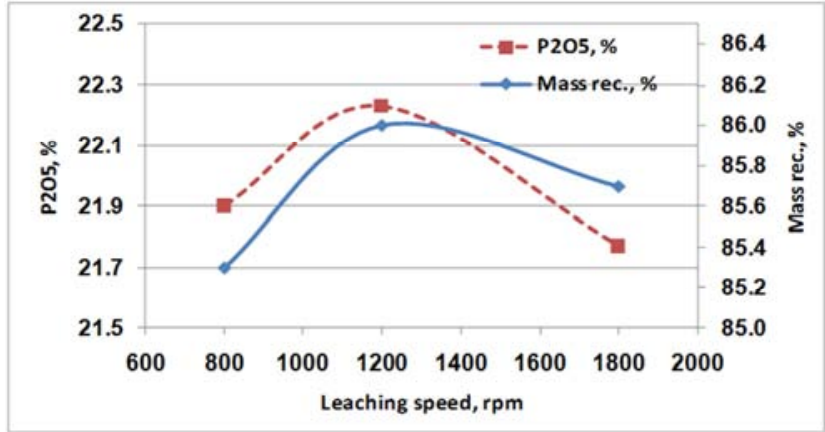

Figure 11. Effect of agitation speed on weight recovery and $\mathrm{P}_{2} \mathrm{O}_{5} \%$.

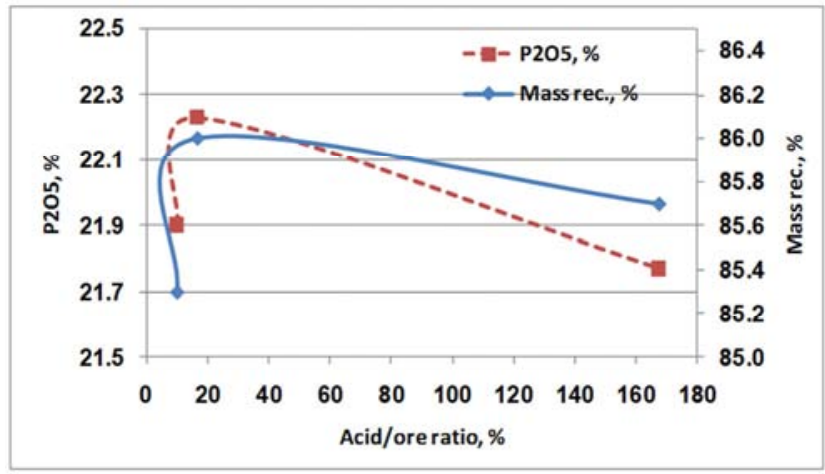

Figure 12. Effect of acid to ore ratio on weight recovery and $\mathrm{P}_{2} \mathrm{O}_{5} \%$. 


\subsection{Leaching of Some Particle Sizes Produced from Grinding Process}

The obtained results are illustrated in Tables $10 \& 11$ and Figure 13. From these results, it can be revealed that leaching process on size $-100 \mu \mathrm{m}$ raised $\mathrm{P}_{2} \mathrm{O}_{5} \%$ from $23.88 \%$ to $28.44 \%$ with weight recovery $84 \%$. The weight recovery and
$\mathrm{P}_{2} \mathrm{O}_{5}$ recovery with respect to the original feed were $28.29 \%$ and $42.39 \%$, respectively. The leaching process on size -250 $\mu \mathrm{m}$ increased $\mathrm{P}_{2} \mathrm{O}_{5} \%$ from $21.42 \%$ to $25.51 \%$ with weight recovery $86.33 \%$. The weight recovery and $\mathrm{P}_{2} \mathrm{O}_{5}$ recovery with respect to the original feed were $51.69 \%$ and $69.47 \%$, respectively.

Table 10. Leaching conditions of some particle sizes produced from grinding process.

\begin{tabular}{lllll}
\hline Acid/ore ratio, $\%$ & Leaching speed, $\mathbf{r p m}$ & Leaching time, min. & S/L ratio, \% & Exp. \\
\hline 10 & 1200 & 15 & 15 & $-100 \mu \mathrm{m}$ \\
10 & 1200 & 15 & 15 & $-250 \mu \mathrm{m}$ \\
\hline
\end{tabular}

Table 11. Final results of leaching process of some sizes produced from grinding process.

\begin{tabular}{|c|c|c|c|c|c|}
\hline $\begin{array}{l}\mathrm{P}_{2} \mathrm{O}_{5} \text { rec. with resp. to } \\
\text { original feed, } \%\end{array}$ & $\mathrm{P}_{2} \mathrm{O}_{5}, \%$ after leaching & $\mathrm{P}_{2} \mathrm{O}_{5}, \%$ before leaching & $\begin{array}{l}\text { Weight recovery with } \\
\text { resp. to original feed, } \%\end{array}$ & Weight recovery, \% & Exp. \\
\hline 42.39 & 28.44 & 23.88 & 28.29 & 84.00 & $-100 \mu \mathrm{m}$ \\
\hline 69.47 & 25.51 & 21.42 & 51.69 & 86.33 & $-250 \mu \mathrm{m}$ \\
\hline
\end{tabular}

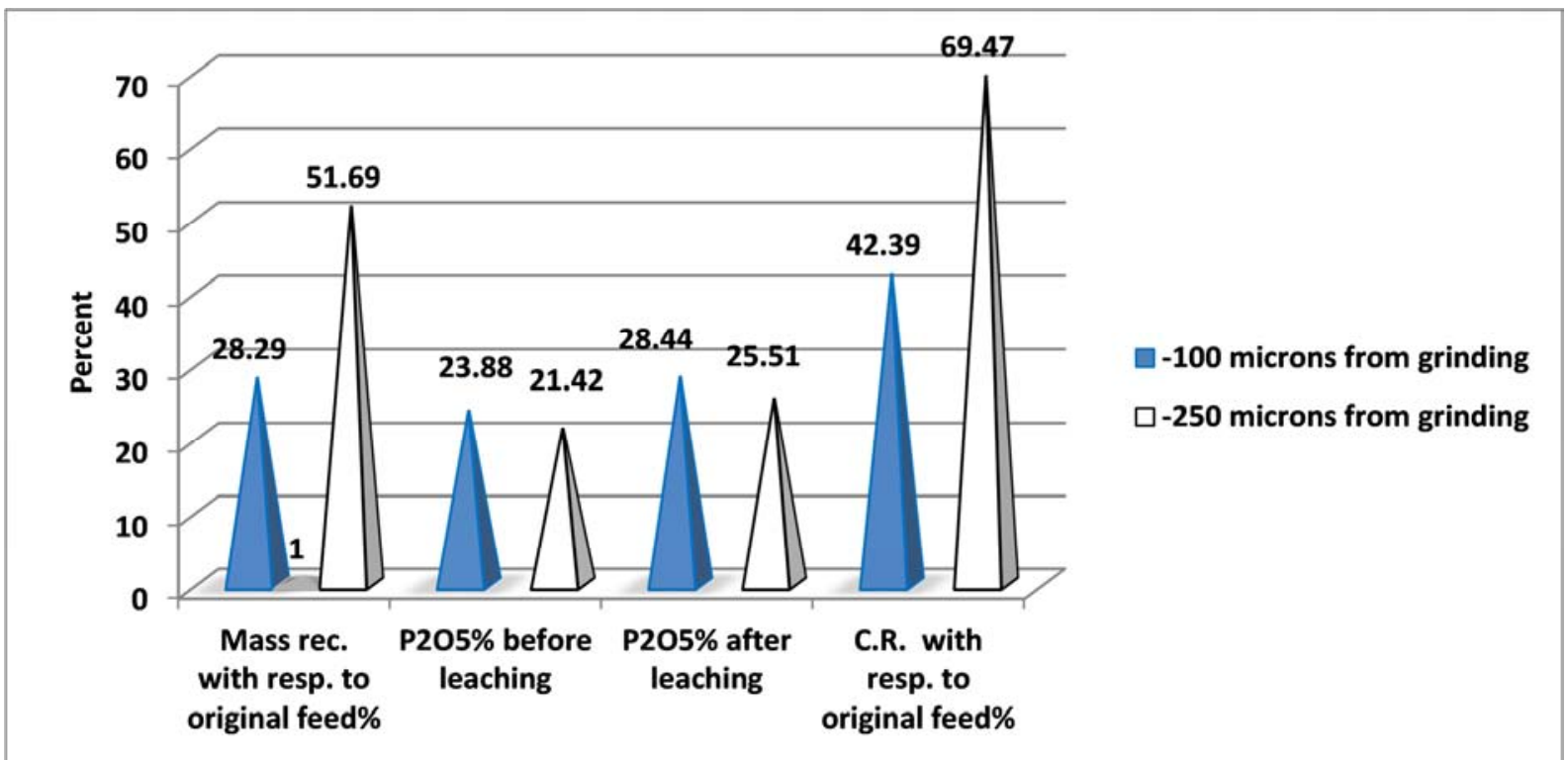

Figure 13. Final results of leaching process of some sizes produced from grinding process.

\section{Conclusions}

Three alternative samples obtained from crushing and sieving were compared to obtain the highest grade of $\mathrm{P}_{2} \mathrm{O}_{5}$ with the greatest recovery. The second option (i.e. sizes below $0.400 \mathrm{~mm}$ ) was the best one where the percent of $\mathrm{P}_{2} \mathrm{O}_{5}$ is $21.17 \%$, recovery of $\mathrm{P}_{2} \mathrm{O}_{5}$ is $15.30 \%$, and weight recovery equals to $13.68 \%$.

The calcination of feed sample upgraded $\mathrm{P}_{2} \mathrm{O}_{5}$ from $18.93 \%$ to $22.4 \%$, with weight recovery of $83.75 \%$, and $\mathrm{P}_{2} \mathrm{O}_{5}$ recovery of $99.10 \%$.

Two options of sizes obtained from grinding and sieving were separated to obtain the highest grade of $\mathrm{P}_{2} \mathrm{O}_{5}$ with the greatest recovery. The first option (i.e. sizes below $100 \mu \mathrm{m}$ ) gave $\mathrm{P}_{2} \mathrm{O}_{5}$ percent of $23.88 \%, \mathrm{P}_{2} \mathrm{O}_{5}$ recovery of $42.37 \%$, and weight recovery equals to $33.68 \%$. The second option (i.e. sizes below $160 \mu \mathrm{m})$ gave $\mathrm{P}_{2} \mathrm{O}_{5}$ percent of $22.52 \%, \mathrm{P}_{2} \mathrm{O}_{5}$ recovery of $53.25 \%$, and weight recovery equals to $44.88 \%$.
Leaching process using acetic acid gave the best results at the following conditions: a)solid to liquid ratio $15 \%$ where the percent of $\mathrm{P}_{2} \mathrm{O}_{5}$ raised from $18 \%$ to $22.23 \%$ with weight recovery about $86 \%$, b) Agitation time 15 minutes where the percent of $\mathrm{P}_{2} \mathrm{O}_{5}$ raised from $18 \%$ to $22.35 \%$ with weight recovery about $86 \%$, c) Agitation speed $1200 \mathrm{rpm}$ where the percent of $\mathrm{P}_{2} \mathrm{O}_{5}$ increased from $18 \%$ to $22.23 \%$ with weight recovery about $86 \%$, d) Acid to ore ratio $16.7 \%$ where the percent of $\mathrm{P}_{2} \mathrm{O}_{5}$ increased from $18 \%$ to $21.44 \%$ with weight recovery about $88.7 \%$.

The leaching process of size $-100 \mu \mathrm{m}$ raised $\mathrm{P}_{2} \mathrm{O}_{5} \%$ from $23.88 \%$ to $28.44 \%$ with weight recovery $84 \%$. The weight recovery and $\mathrm{P}_{2} \mathrm{O}_{5}$ recovery with respect to the original feed were $28.29 \%$ and $42.39 \%$, respectively. The leaching process on size $-250 \mu \mathrm{m}$ increased $\mathrm{P}_{2} \mathrm{O}_{5} \%$ from $21.42 \%$ to $25.51 \%$ with weight recovery of $86.33 \%$. The weight recovery and $\mathrm{P}_{2} \mathrm{O}_{5}$ recovery with respect to the original feed were $51.69 \%$ and $69.47 \%$, respectively. 


\section{Acknowledgements}

The present research work was supported by the Egyptian Academy of Science and Technology with Assiut University, Faculty of Engineering to establish Centre of Evaluation and Upgrading Ores in South Valley (grant \# 37). The authors would like to thank Eng. Nourhan Ashraf Mahmoud, Assistant lecturer at Mining \& Metallurgical Engineering Dept. Technicians in mineral processing labs are also appreciated.

\section{References}

[1] Mohammadkhani, M., Noaparast, M., Shafaei, S. Z., Amini, A., Amini, E., Abdollahi, H., "Double reverse flotation of a very low grade sedimentary phosphate rock, rich in carbonate and silicate", International Journal of Mineral Processing, 100 (2011), 157-165.

[2] Gharabaghi, M., Noaparast, M., Irannajad, M., 2009. Selective leaching kinetics of lowgrade calcareous phosphate ore in acetic acid. Hydrometallurgy 95, 341-345.

[3] Abdel-Zaher, M. A., 2008. Physical and thermal treatment of phosphate ores - an overview. Int. J. Miner. Process. 85, 5984.

[4] Jasinski, S. M., 2007. Phosphate Rock. USGS 120-121.
[5] Sengul, H., Ozer, K., Gulaboglu, M. S., 2006. Chem. Eng. J. $122(3), 135-140$.

[6] El-gillani, D. A., Abouzeid, A.-Z. M., 1993. Int. J. Miner. Process. 38, 235-256.

[7] Sis, H., Chander, S., 2003. Reagents used in the flotation of phosphate ores: a critical review. Miner. Eng. 16, 577-585.

[8] Abouzeid, A. Z. M., Negm, A. T., Elgillani, D. A., 2009. Upgrading of calcareous phosphate ores by flotation: effect of ore characteristics. Int. J. Miner. Process. 90, 81-89.

[9] Al-Fariss, T. F., El-Nagdy, K. A., Abdel-Aleem, F. A., ElMidany, A. A., 2013. Column versus mechanical flotation for calcareous phosphate fines upgrading. Part. Sci. Technol. 5, 488-493.

[10] Negm, A. A., Abouzeid, A.-Z. M., 2002. Utilization of East Seba'eya Phosphate Plant Taillings. Final Report to The Academy of Scientific Research and Technology.

[11] Elgillani, D. A., Abouzeid, A.-Z. M., Negm, A. A., 1984. Final Report to the Supreme Council of Universities (FRCU) of Egypt.

[12] Ahmed, A. A., 1999. 6th International Conference on Mining. Petroleum, and Metallurgy vol. 1-B, 126-154.

[13] Gu, Z., 2002. "Fine Particle Flotation for Florida Dolomitic Phosphate Pebbles.", M.Sc. Thesis, College of Engineering and Mineral resources, West Virginia University. 